\title{
Are Specific Gene Expressions of Extracellular Matrix and Nucleus Pulposus Affected by Primary Cell Cultures Prepared from Intact or Degenerative Intervertebral Disc Tissues?
}

\author{
Numan KARAARSLAN ${ }^{1}$, Ibrahim YILMAZ2, Hanefi OZBEK ${ }^{2}$, Duygu YASAR SIRIN³ ${ }^{3}$ Necati KAPLAN ${ }^{4}$, \\ Yener AKYUVA ${ }^{5}$, Aylin GONULTAS ${ }^{6}$, Ozkan ATES ${ }^{7}$

\begin{abstract}
${ }^{1}$ Namik Kemal University, School of Medicine, Department of Neurosurgery, Tekirdag, Turkey 'Istanbul Medipol University School of Medicine, Department of Medical Pharmacology, Istanbul, Turkey

${ }^{3}$ Namik Kemal University Faculty of Arts and Sciences, Department of Molecular Biology and Genetic, Tekirdag, Turkey ${ }^{4}$ Istanbul Rumeli University, Corlu Reyap Hospital, Department of Neurosurgery, Tekirdag, Turkey

${ }^{5}$ Gaziosmanpasa Taksim Research and Training Hospital, Department of Neurosurgery, Istanbul, Turkey

${ }^{6}$ Haydarpasa Numune Research and Training Hospital, Department of Pathology, Istanbul, Turkey

${ }^{7}$ Istanbul Esenyurt University, Esencan Hospital, Department of Neurosurgery, Istanbul, Turkey
\end{abstract}

\section{ABSTRACT}

AIM: To determine the gene expression patterns of nucleus pulposus (NP) in cell cultures obtained from degenerated or intact tissues.

MATERIAL and METHODS: Whereas 12 of the cases were diagnosed with lumbar disc herniation and had undergone lumbar microdiscectomy, 12 cases had undergone traumatic intervertebral discectomy and corpectomy, along with discectomy after spinal trauma. NP-specific markers and gene expressions of the reagents of the extracellular matrix in the experimental setup were tested at the $0^{\text {th }}, 24^{\text {th }}$, and $48^{\text {th }}$ hours by quantitative reverse transcriptase polymerase chain reaction (qRT-PCR). Visual evaluations were simultaneously made in all samples using invert and fluorescence microscopy. Vitality and proliferation analyses were evaluated by UV spectrophotometer. As a method of statistical evaluation, Spearman was used for categorical variants, and the Pearson correlation was used for variants with numerical and plain distribution.

RESULTS: No association was found either between the tissue type and times $(r=0.000 ; p=1.000)$ or between the region that the tissue was obtained from and hypoxia transcription factor- 1 alpha (HIF-1a) gene expression $(r=0.098 ; p=0.245)$. There was no correlation between cell proliferation and chondroadherin (CHAD) expression or between type II collagen (COL2A1) and CHAD gene expressions. It was found that CHAD and HIF-1a gene expressions and HIF-1a and COL2A1 gene expressions affected cell proliferation.

CONCLUSION: Cell culture setups are of paramount importance because they may influence the pattern of changes in the gene expressions of the cells used in these setups.

KEYWORDS: Annulus fibrosus, Degenerative disc disease, Nucleus pulposus, Specific marker, Pharmaco-molecular therapy, Human primary cell culture

ABBREVIATIONS: AF: Annulus fibrosus, AO/PI: Acridine Orange/Propidium lodide, CHAD: Chondroadherin gene, COL2A1: collagen type II, DMEM: Dulbecco's Modified Eagle's medium, HBSS: Hank's balanced salt solution, H\&E: Hematoxylin \&Eosin, HIF1a: Hypoxia-inducible factor 1-alpha, hTERT: Human telomerase reverse transcriptase gene; IVD: Intervertebral disc degeneration, MEM: Minimum essential medium, MTT: (3-[4,5-dimethyltiazol-2-yl]-2,5-diphenyltetrazolium bromide); NP: Nucleus pulposus, OD: Optical density, qRT-PCR: Quantitative reverse transcriptase polymerase chain reaction, SPSS: Statistical Package for the Social Sciences. 


\section{INTRODUCTION}

$\mathrm{R}$ egenerative research into the treatment of degenerative intervertebral discs aims to halt degenerative processes or sustain regeneration by reversing such processes. However, it is known that repair of damaged cells is not possible (10).

In intervertebral disc degeneration (IVD), which occurs due to annulus fibrosus (AF) and/or damage in nucleus pulposus (NP) tissues, negative outcomes may occur after pathological processes ruin physiological continuance. These outcomes may include functional losses in addition to economical, emotional, and workforce losses for both patients and their relatives (18).

The results of the current methods used in surgeries are not very promising (1). To this end, new methods are on trial, such as three-dimensional printing scaffolds in which stem cells are imbrued, gene treatments, and nanotechnology $(16,22,26)$.

It has been reported in the literature that painful inflammation may accompany immunopathological processes in disc degeneration. It has been emphasized that NP cells (NPC) plays a significant role in the repair of intervertebral discs by organizing expressions of inflammatory, anabolic, catabolic, and anti-catabolic cytokines. It has been reported that the pharmacogenomic treatments may prove successful in the repair of human NPC damage by using lentiviral and adenoviral systems which may be important due to the genome convergence and side effect. It is important to form new gene treatment approaches in IVD disorders that are safer and less immunogenetic (17).

Studies have also reported that spinal disorders occur due to the NPCs damages stemming from the degeneration of the intervertebral disc which has the most avascular structure in humans (32). Recently, it has been underlined that autologous NP cell applications may be a potential alternative treatment method for IVD among the alternative treatment methods. However, single-layer expression of cell cultures may negatively affect matrix products in tissues obtained from different surgical samples (23). In this case, cell culture setups play and important role in changes in gene expression levels (15).

Thanks to cell based setups, it has been possible to carry out many studies, such as investigations into the repair of damaged genes and/or gene silencing, production of various enzymes and hormones, effects of drugs on the cell cycle, behavior of drug-induced receptor complexes, measurement of inner cell activity, signal transmit mechanisms, cytogenetic analyses, cytotoxicity, genetic manipulation, and immortalization (25).

In addition, there are few studies concerning cellular subgroups in mature NP. A detailed understanding of the ontogenetic, cellular, and molecular features of the IVD cell population is crucial in IVD regeneration and cell replacement treatments (27).

It has been reported that the role of NP cell proliferation in the pathogenesis of the intervertebral disc degeneration is not clearly elucidated. Liu et al. reported that microRNAs, being a branch of small, noncoding RNAs, regulates cell proliferation in several pathological states and upregulates abnormal miR21 in disc degeneration (14).

By means of the findings obtained from above studies, it will be possible to discover viable cell treatments. However, before stem cells are used for therapeutic purposes, cells must locate the damaged region and maintain their vitality, where they can adhere and finally differentiate to the target cell type.

As it is known, nowadays, the infrastructural studies of experimental researches on specialized cellular treatments have gained momentum. Not only surgical methods that can treat mechanical problems of the intervertebral disc damage but also pharmacokinetic and pharmacogenomic studies for biological and genetic repair with regenerative and reparative methods have gained popularity in the field of neurosurgery. In this way, it may be possible to repair the damaged disc tissue thoroughly. Such studies are carried out either on degenerated disc tissue or on intact disc tissues. Therefore, in this study, human primer cell cultures were constructed using both disc tissues. The present study aims to discover whether the source of cells prepared for use in the treatment of IVD-whether from degenerated or from intact tissueshas any effect on the gene expression of CHAD $(4,23), \mathrm{HIF}-1 \mathrm{a}$ (NP specific markers) (5), and COL2A1 protein (responsible for and specific to matrix development) (33). The second aim of this study is to provide necessary preliminary data with the neurosurgeons and orthopaedic surgeons who will perform molecular studies for spine tissue.

\section{MATERIAL and METHODS}

This study was carried out with the approval of the local ethical committee (Namik Kemal University 30.03.2017) and consent forms were obtained from the volunteers.

\section{Study Design}

After obtaining monolayer cell cultures, cells were counted in Trypan blue (Cat no: T8154 Sigma) through a neubauer chamber. Then $9 \times 10^{5}$ cell/well transferred into six-well plates. MTT analysis (3-[4,5-dimethyltiazol-2-yl]-2,5-diphenyltetrazolium bromide) (MTT Cell Proliferation Assay Cat\# V-13154, Cell Biolabs Inc., USA) was performed at the $0^{\text {th }}, 24^{\text {th }}$, and $48^{\text {th }}$ hours.

In each group, expressions of CHAD, COL2A1, and HIF1a were evaluated with quantitative reverse transcriptase polymerase chain reaction (qRT-PCR). The data were statistically evaluated.

\section{Resection and Histopathological Evaluation of Tissues}

Before cell cultures were set up, degenerated disc tissues that had been resected in an operation were histopathologically evaluated. It was controlled whether tissues to be used in cell cultures were degenerated or not.

Group 1 included cases with herniated (degenerated) lumbar discs. This group contained patients with degenerated NP tissues who were admitted to the neurosurgery clinic with complaints of back and/or leg pain. Afterwards, they underwent operations following a neurological examination and subsequent radiological imaging $(n=25)$ (Figure 1A, B). 
Tissues from patients with Parkinson's disease, those taking antidepressants, and those with a history of treatment with monoamine oxidase inhibitors for the last 14 days were excluded from the present study $(7,8,12,19)$. Moreover, tissues from cases displaying malignancy were not included in the study. Tissues of patients who did not respond to current conservative treatment and had undergone lumbar microdiscectomy were included in the study $(n=12)$.

Group 2 included cases with intact NP tissues. These cases had presented to the emergency department with spinal trauma $(n=14)$. These patients underwent operation after neurological examination and radiological imaging. In these cases, intact NP tissues were obtained from traumatic herniated intervertebral disc tissues and from adjacent healthy disc tissues already excised during corpectomy $(n=12)$.

Resected tissues from lumbar microdiscectomy operations were divided into two to be sent to the laboratory. These divided tissues were cut equally into pieces, which were referred to as superior and inferior. The superior and inferior parts of these tissues were sent to the laboratory. Tissue samples to be pathologically evaluated were transferred into petri plates containing $10 \%$ formalin. The samples taken for cell culturalization were transferred into falcon tubes containing DMEM and penicillin streptomycin. Letter coding was used to ensure that researchers were blind to the samples in both laboratories.

\section{Histopathological Evaluation}

Tissue pieces sent to the pathology laboratory for histopathological evaluation were sampled after their macroscopic definition. Tissue pieces were embedded into paraffin-embedded blocks. Five-micrometer pieces were taken from the paraffinembedded blocks and stained with hematoxylin and eosin (H\&E) and Alcian Blue-Pas (ABP). They were observed by means of light microscope at different magnifications.

Chondrocyte proliferation, delaceration, cleft formation, granular change, and mucus degeneration were seen in fibrocar- tilaginous tissue fragments during microscopic evaluation $(21,31)$ (Figure 2A-D).

\section{Preparation of Cell Cultures from Tissues}

Tissues obtained from two different anatomic regions were put into falcon tubes containing $5 \%$ penicillin-streptomycin and DMEM under appropriate conditions. Tissues in the flow cabin were washed by sterile phosphate buffer saline (PBS) solvent, and red blood cells were cleaned.

The samples were shivered mechanically. These tissues were then incubated overnight after addition of Clostridium histolyticum based collagenase type I $(475 \mu \mathrm{g} / \mathrm{mL})$ and type II (125 $5 \mu \mathrm{g} / \mathrm{mL}$ ) enzymes, which were solubilized in HBSS. The tissues that were enzymatically digested were centrifuged at $4^{\circ} \mathrm{C}$ and $1,300 \mathrm{rpm}$ for 10 minutes. Cell pellets at the bottom of the centrifuge were re-suspended using the culture medium that had been prepared by DMEM. After the samples were transferred to the flasks, they were left in incubation for 72 hours. The degenerated and healthy samples in NPCs/AFCs obtained from humans were transferred into wells and fed for 21 days.

\section{Imaging with Invert and Fluorescence Microscopy}

An inverted light microscope (Olympus, CKX41) was used to monitor cell cultures, and a fluorescent microscope (Leica; DM 2500) was used for acridine orange/propidium iodide (AO/PI) analysis. Microphotographs of the cell organizations were obtained before and during applications. The images were evaluated using the Cytovision Capture Station imaging program.

\section{Tests of Viability and Proliferation}

Viability tests were performed by MTT kit in conformity with the manufacturer's instructions. The MTT kit is based on the principle that blue formazan crystals are formed by means of dehydrogenase enzymes, which is in tetrazolium rings, which makes it impossible for formazan crystals to form in in dead cells. By means of a pipette gun, feedlots were removed at the $0^{\text {th }}, 24^{\text {th }}$, and $48^{\text {th }}$ hours in a dark environment.
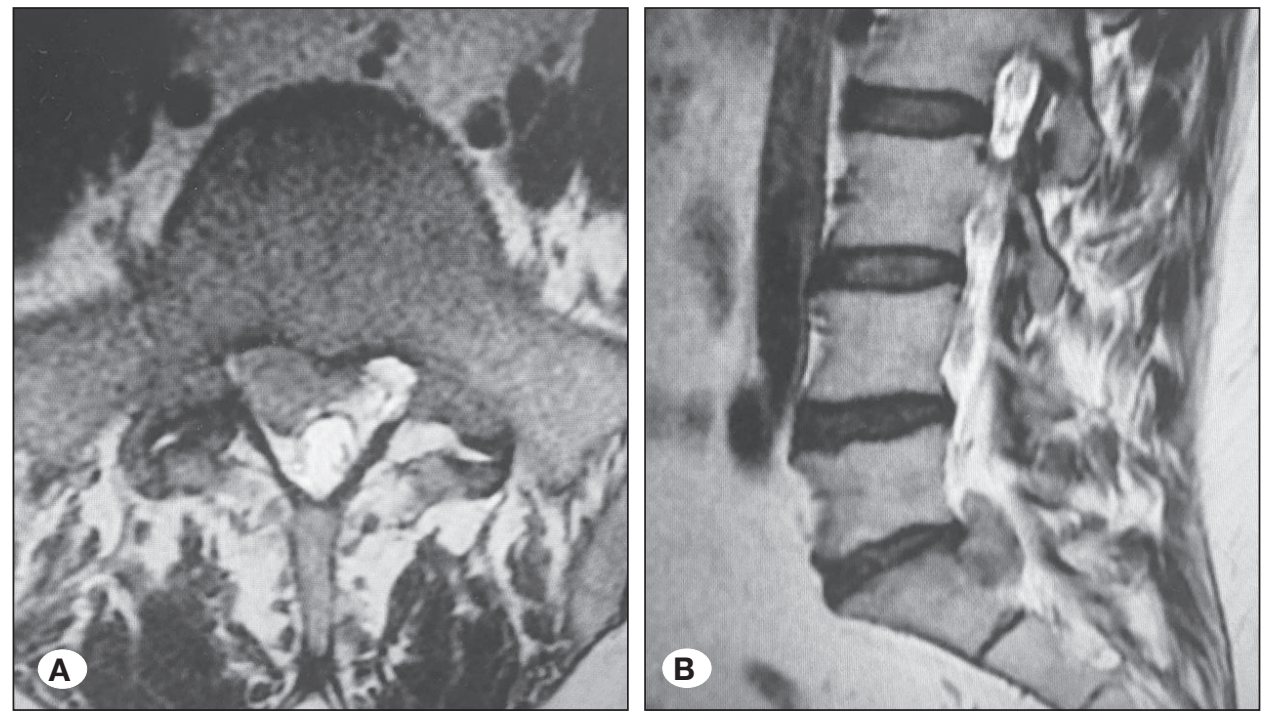

Figure 1: T2 weighted axial (A) and sagittal (B) MR images of the patient reveal an almost-free disc fragment extruded from the L5-S1 intervertebral disc space, which was obtained for the study and actually contains both annulus fibrosis and nucleus pulposus. 

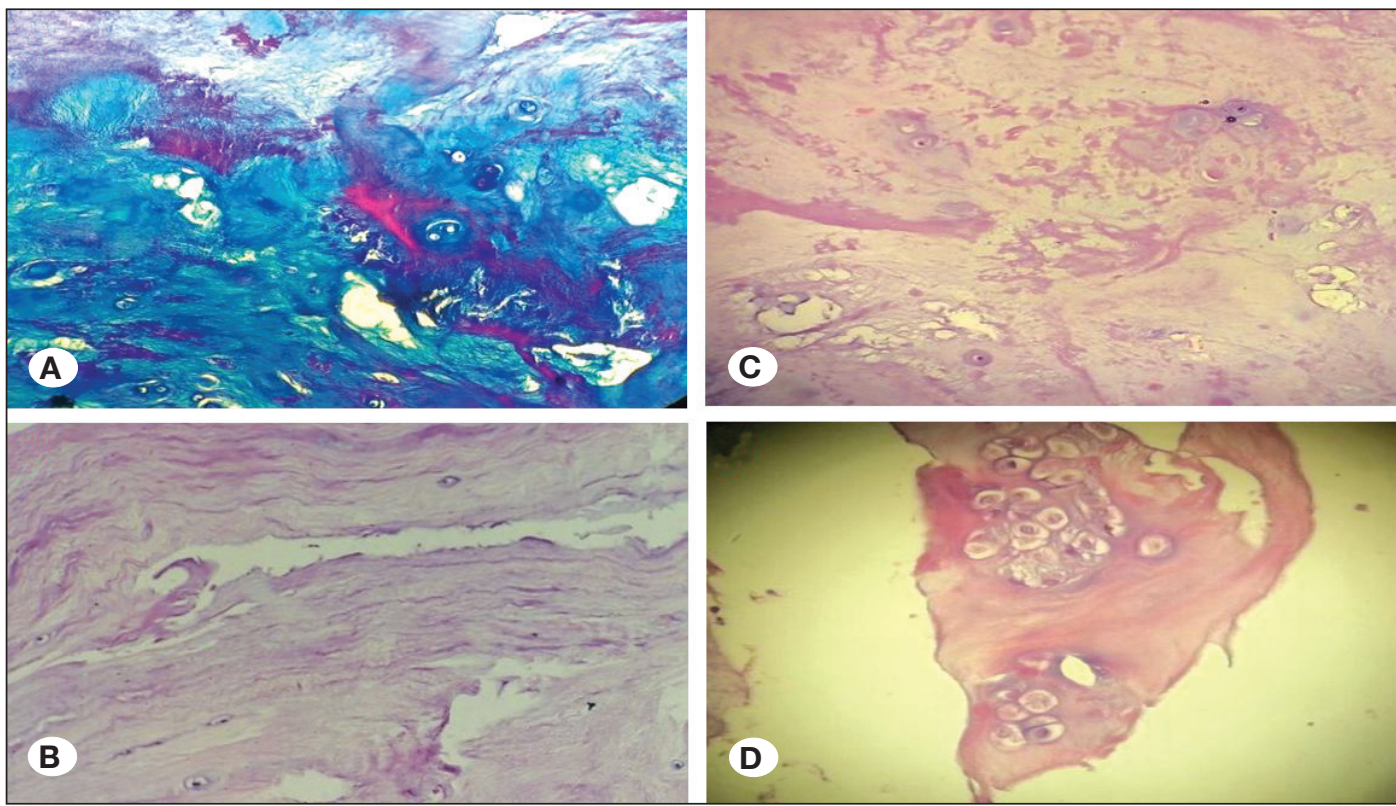

Figure 2: In the resects obtained from a 56-yearold patient with a lumbar disc herniation.

A) Mucous degeneration in NP (Alcian-Blue PAS, X200). B) Granular change in NP (H\&E, X200). C) Laceration and slit formation in AF (H\&E, X200). D) In the resects obtained from a 26-yearold patient with disc herniation, chondrocyte, cell proliferation in NP was found (H\&E, X400).
Thus, 300- $\mu \mathrm{L}$ of MTT, which was diluted in DMEM, was added into each well. After the incubation, which took $170 \mathrm{~min}$, each well was added into DMSO. Samples were put into ELISA and assessed at $540 \mathrm{~nm}$ optical density (OD). Living cell reproduction was calculated in $\%$ by the following proliferation test: [(Test OD)/(Control OD) $\times 100](7,8,12,19)$.

At the $0^{\text {th }}$ hour, the percentage of living cells was accepted as $100 \%$. The number of living cells was calculated at the $24^{\text {th }}$ and $48^{\text {th }}$ hours, and the researchers analyzed whether there was a difference among groups in terms of proliferation.

\section{Preparation and Application of the AO/PI}

The AO/PI stain was prepared using $10 \mathrm{~g}$ of sodiumethylenediaminetetraacetic acid, $4 \mathrm{mg}$ of $\mathrm{Pl}, 50 \mathrm{ml}$ of fetal calf serum, and $4 \mathrm{mg}$ of $\mathrm{AO}$ (dissolved in $2 \mathrm{ml} 99 \%$ Ethanol). They were mixed well. Then, sterile distillated water was added to reach $200 \mathrm{ml}$ as the final volume.

By means of the nucleic acid binding dyes $A O$ and $\mathrm{PI}$, the researchers accurately determined cell viability. $A O$ is an intercalating stain that can permeate in both living and dead cells. AO stains all nucleated cells and generates green fluorescence. PI can only enter dead cells with poor membrane integrity, and it stains all dead nucleated cells to generate red fluorescence. Thus, when cells are stained with both $\mathrm{AO}$ and $\mathrm{PI}$, all live nucleated cells fluoresce green and all dead nucleated cells fluoresce red.

\section{Evaluation of NP-specific Markers by qRT-PCR}

PCR amplification was performed in accordance with the method that was previously described. Total RNA was isolated using a PureLink ${ }^{\circledR}$ RNA Mini Kit in conformity with the manufacturer's instructions. To obtain cDNA, $50 \mathrm{ng}$ of RNA was reverse transcribed with a High-Capacity cDNA Reverse Transcription Kit (Thermo Fisher Scientific, Cat\#4368814) using a thermal cycler (ProFlex, Thermo Fisher Scientific).
All genes were amplified using TaqMan ${ }^{\circledR}$ Gene Expression Assays for CHAD (Hs00154382_m1, Cat\#4448892), HIF-1a (Hs00153153_m1, Cat\#4453320), COL2A1 (Hs00264051_m1, Cat\#4453320), and internal control gene ACTB (Hs99999903_ $\mathrm{m1}$, Cat\#4453320). A real-time PCR reaction mix was prepared with $1 \mathrm{ml}$ of TaqMan Gene Expression Assay, $10 \mathrm{ml}$ of TaqMan Gene Expression Master Mix (Cat\#4369016), $4 \mathrm{ml}$ of cDNA template, and UltraPure DNase/RNase-Free Distilled Water (Cat\#10977035) were used for each gene in MicroAmp Fast Optical 96-Well Reaction Plates (Cat\#4346906).

The reaction protocol was as follows: two-minute hold at $50^{\circ} \mathrm{C}, 10$-minute hold at $95^{\circ} \mathrm{C}, 15$ seconds at $95^{\circ} \mathrm{C}$, and one minute at $60^{\circ} \mathrm{C}$ for 40 cycles, all performed with an Applied Biosystems 7300/7500 Real-Time PCR System.

\section{Statistical Analysis}

Statistical analyses were performed by SPSS version 18.0. Data were given as percentage (\%), mean, and standard deviation. Spearman was used for categorical variables, whereas Pearson was used for numerical and normal variables. $p<0.05$ was accepted as statistically significant.

\section{RESULTS}

Morphological evaluation of cell cultures revealed that normal healthy and proliferated large chondrocytes, as well as areas containing cell types having chondrocyte-like extrafibrillary zones called giant chondrons. Structures with normal extracellular matrix were identified around these areas (Figure 3).

There was no relationship between tissue-time $(r=0.000$; $p=1.000)$ and tissue-HIF-1a $(r=0.098 ; p=0.245)$. There was a significant relationship between other binary combinations [Tissue-MTT ( $r=0.275 ; p=0.001)$; Tissue-CHAD ( $r=0.293$; $p=0.000)$ and Tissue-COL2A1 $(r=0.447 ; p=0.000)]$. 
Table I: Spearman Correlation Analysis

\begin{tabular}{|c|c|c|c|c|c|c|c|}
\hline & & & Time & MTT & CHAD & HIF-1a & COL2A1 \\
\hline \multirow{6}{*}{ Spearman's rho } & \multirow{3}{*}{ Tissue } & Correlation Coefficient & .000 & $.275^{\star *}$ & $.293^{* *}$ & .098 & $.447^{* *}$ \\
\hline & & Sig. (2-tailed) & 1.000 & .001 &, 000 & ,245 & .000 \\
\hline & & $\mathrm{N}$ & 144 & 144 & 144 & 144 & 144 \\
\hline & \multirow{3}{*}{ Time } & Correlation Coefficient & & $.410^{* *}$ & $.239^{* *}$ & $-.837^{\star *}$ & $-.548^{* \star}$ \\
\hline & & Sig. (2-tailed) & & .000 & .004 & .000 & .000 \\
\hline & & $\mathrm{N}$ & & 144 & 144 & 144 & 144 \\
\hline
\end{tabular}

**(significant correlation).

Table II: Pearson Correlation Analysis

\begin{tabular}{|c|c|c|c|c|}
\hline & & CHAD & HIF-1a & COL2A1 \\
\hline & Pearson Correlation & .095 & $-.379^{\star *}$ & $-.195^{*}$ \\
\hline \multirow[t]{3}{*}{$\mathrm{MTT}$} & Sig. (2-tailed) & .258 & .000 & .019 \\
\hline & $\mathrm{N}$ & 144 & 144 & 144 \\
\hline & Pearson Correlation & & $.194^{*}$ & .085 \\
\hline \multirow[t]{3}{*}{ CHAD } & Sig. (2-tailed) & & .020 & .312 \\
\hline & $\mathrm{N}$ & & 144 & 144 \\
\hline & Pearson Correlation & & & $.796^{* *}$ \\
\hline \multirow[t]{2}{*}{ HIF-1a } & Sig. (2-tailed) & & & .000 \\
\hline & $\mathrm{N}$ & & & 144 \\
\hline
\end{tabular}

*, **(significant correlation).

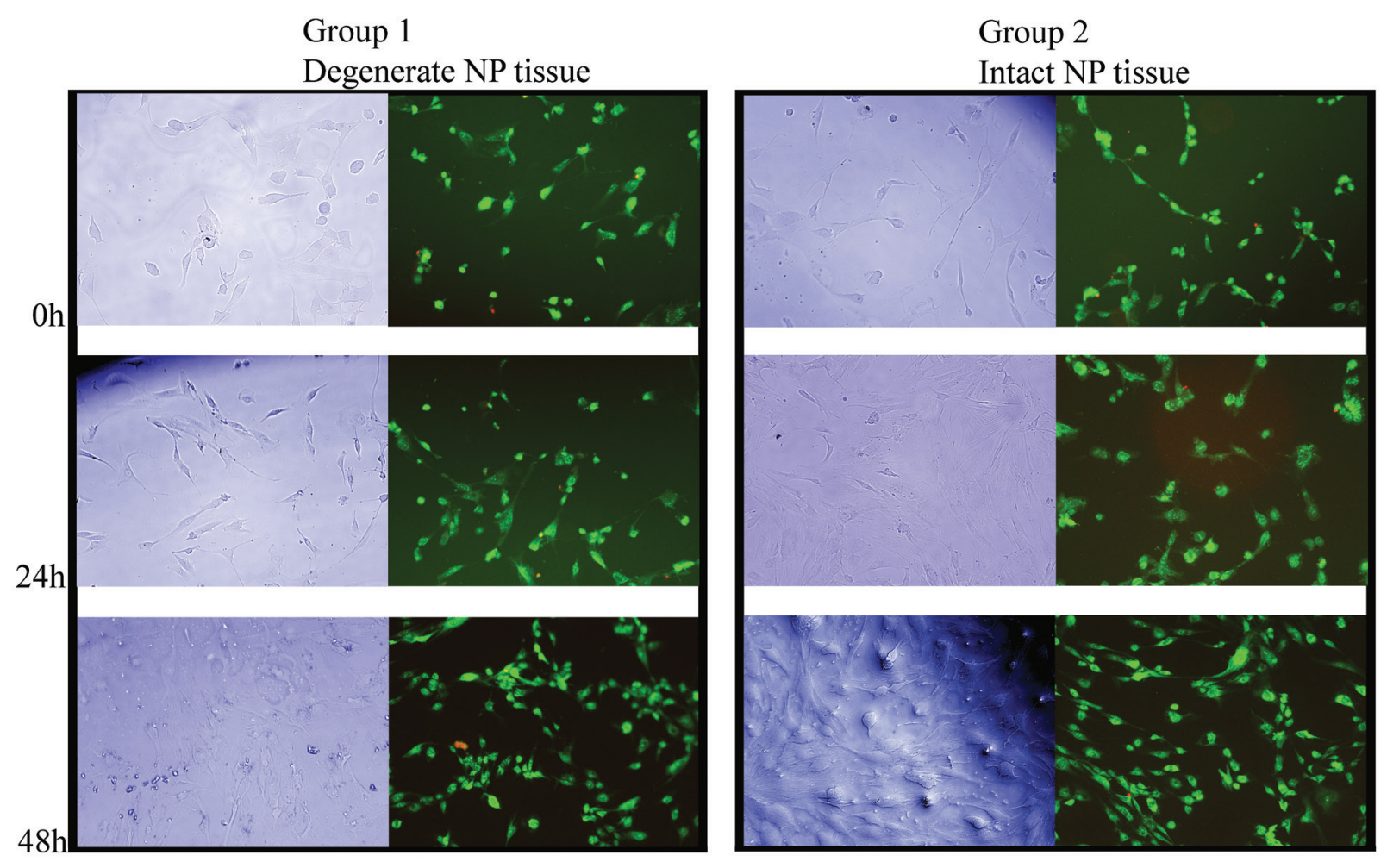

Figure 3: Acridine Orange /Propidium lodite (AO/PI) staining at specifictine points in both groups. 
A significant relationship was found among all variables except those of proliferation time and tissue type. The relationships between time and HIF-1a expression and time and COL2A1 expression were negative [Time-MTT $(r=0.410 ; p=0.000)$; Time-CHAD ( $r=0.239$; $p=0.004)$; Time- HIF-1a $(r=-0.837$; $\mathrm{p}=0.000)$; Time-COL2A1 $(r=-0.548 ; \mathrm{p}=0.000)]$ (Table I, II).

The relationships among MTT-HIF-1a, MTT-COL2A1, CHADHIF-1a, and HIF1a-COL2A1 were $(r=-0.379 ; p=0.000),(r=-$ $0.195 ; p=0.019),(r=0.194 ; p=0.020)$, and $(r=0.796 ; p=0.000)$, respectively. They were reported to be significant (Figure 4).

\section{DISCUSSION}

Due to the gradual increase in the interest related to the sport activities, permanent or temporary injuries may result from direct or indirect traumas, such as strokes and falls (12). In addition, NP damage related to high-energy trauma or lowenergy spinal trauma may occur as result of overtaxed NP (30).

IVD, which occurs due to NP tissue damage and affects people's lives adversely, is known to induce high health costs (18). Current methods against disc degeneration are surgical and conservative. They aim to remove symptoms of the pathology and maintain the functions of the vertebra.

It has been reported that mechanical load on intervertebral discs changes matrix features and affects disc cell metabolism. As a result, degenerative disc disease occurs, and discogenic pain develops (6). However, it is highlighted that little is known about the question how such changes have been inducted at the molecular level (6).
Previous studies have found that NPCs within the intervertebral disc structure directly result from embryonic notochords. It has been emphasized that a change in NPC population in humans may lead to spine disorders, and changes to the extracellular matrix may result in similar results as people grow older. It is underscored that how environmental factors affect cell functions has also yet to be adequately understood to determine the bases of these changes (20).

The long-term treatment modality targets the biological regeneration of the NP tissue, which is found in the central of the intervertebral disc tissue. The cell-based researches at the pharma-molecular level aiming to cure IVD may be promising in this field. For this reason, the use of injectable material and/ or stem cells via endoscopic methods has been examined in order to place them in the center of the treatment. The authors of the present study aimed to determine the adhesion features, proliferation capacity, and phenotype capacity of stem cells. The researchers also sought to identify genes that native IVD cells express specifically. Thus, qRT-PCR methodology was used in addition to MTT-ELISA and inverted microscopy analyses.

Studies concerning cells of culturized IVD tissue and mesenchymal stem cells have been gaining popularity. There are some studies indicating that cells in the environment reproduce in colonies with a roundish shape, a dark area in the center, and radiant boundaries $(8,11)$. Such studies underline that these cell colonies are mostly healthy. In addition, colonies in culture environments, in which flatter shapes and cells are surrounded by fibroblast-like cells, may be taken as signs of differentiation.

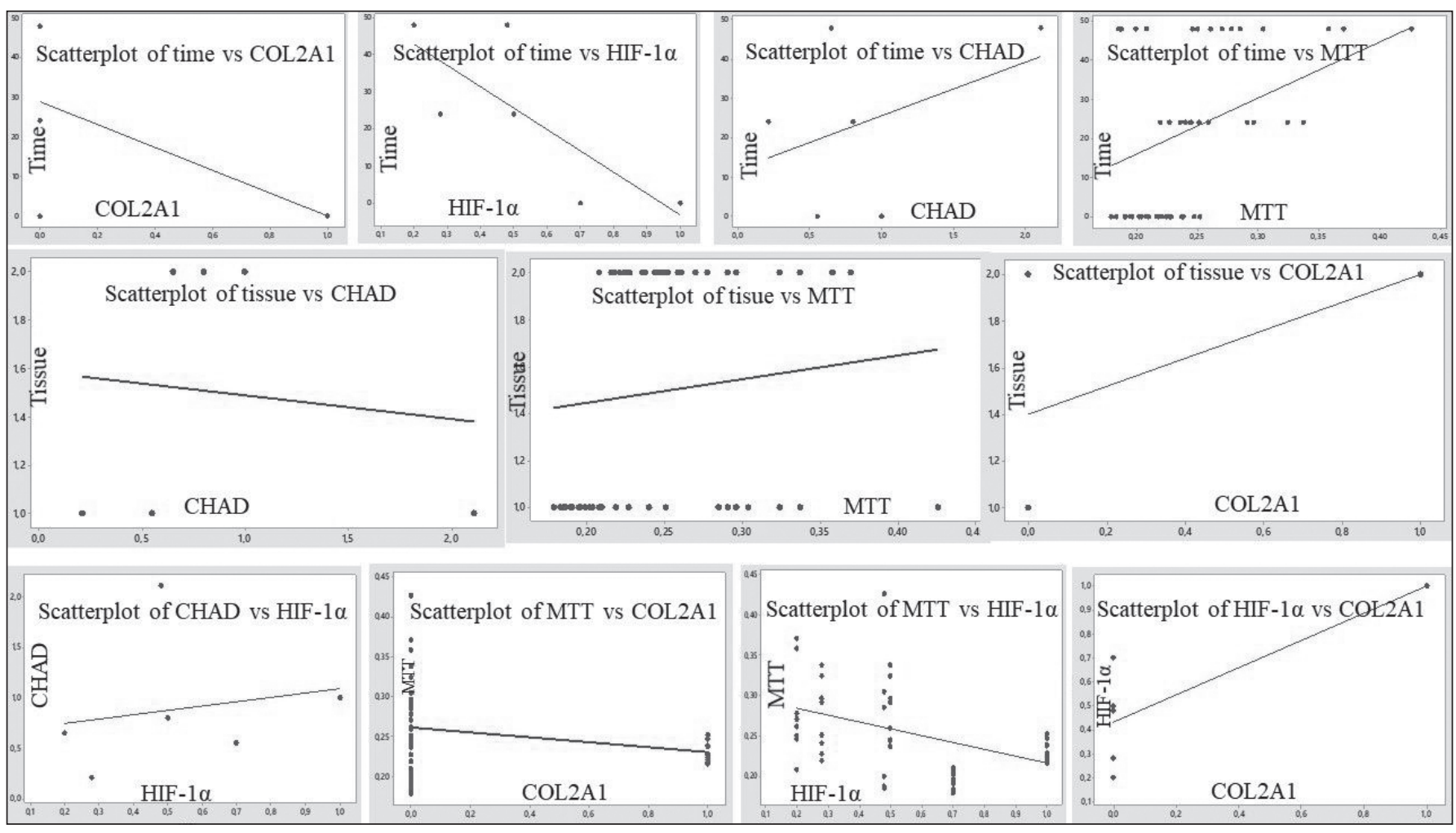

Figure 4: Scatterplot graphs showing the relationship between independent variables. 
However, cell colonies should not be allowed to grow excessively unless necessary. Although cells can be distinguished via staining methods, it is essential that results be confirmed by gene expression analyses (8). The authors of the present study also analyzed gene expressions using qRT-PCR methodology.

Xiong et al. indicated that p53 is a popular tumor suppressor gene and plays a key role in cell metabolism. They reported that p53 level decreased and leaked towards the cell cytoplasm as the level of glucose increased, contrary to p53 level, which increased and condensed in the nuclei of cancer cells. They emphasized that when p53 activity was compared with decreased NP cells, relatively higher levels of p53 expression inhibited autophagia and pentose and phosphate paths in ordinary control NP cells. Moreover, they emphasized that SOX 9 and Col2A1 expressions were more than suppressed p53 NP cells. They concluded that an increase in p53 expression helps NP cells maintain cell integrity and vitality (32).

In the present study, there was no correlation between cell proliferation and CHAD expression. However, there was a significant correlation between CHAD gene expression and HIF-1a gene expression. Similarly, the correlation between HIF-1a and COL2A1 expressions was statistically significant.

The authors' literature review suggests that there are no studies indicating a potential treatment modality for IVD $(3,9,23,34)$.

Zhu et al. underlined that because IVD results from the region where NP tissues originate, obtaining many active NP cells is crucial for both research and IVD treatment. They worked on human induced pluripotent stem cells (IPSCS), using degenerated NPCs in the experimental group, whereas they used leather fibroblast-based IPSCS cells. They observed that IPSCSs, which originate from NP cells, induced the synthesizing of pluripotent markers in normal karyotype, NPcell specific matrix protein and related genes. They maintained that IPSCSs, which were produced from NPC cells that are peculiar to IVD cases, could be treated by a carrier scaffold (such as hydrogel) in IVD cases (34).

The present study did not focus on IPSCSs, but on primary cell culture setups. Thus, the researchers not only examined one single cell but also the cell structures around it. In addition, the researchers observed changes resulting from the extra cellular matrix structure. As the cell cultures used as a control group, the researchers did not test fibroblast cell type tissues, which were different from NP/AF. Instead, the present study tested the cultures obtained from intact NP/AF tissues.

Rosenzweig et al. used freshly prepared isolated cell cultures that they obtained from cattle and human beings (23). They compared matrix products, gene expression profiles, and proliferation of NPCs in both cell cultures. They reported that NP differentiation decreased in cases where COL2A1, Aggrecan, and CHAD decreased. However, they found that COL2A1, Aggrecan, and CHAD levels were maintained on a significantly high level in continuous cultures they prepared by serial sections (23). Most importantly, they emphasized the presence of lower COL2A1, Aggrecan, and CHAD levels than those of standard cultures in human intervertebral disc cell cultures which had been isolated from acute disc herniation cases. They indicated that they found different responses from cattle and human NPCs in pre-clinic research and underlined the importance of selecting animal models and cell sources (23).

In the present study, the researchers did not use any other living mammals. We only used human primary cultures because there may be some differences between human and animal tissue in terms of sensitivity, which may result in misleading results. Moreover, in experimental studies in which commercial cell line systems are used, the use of one single cell type and complex coordination of cells with their micro environment pose problems. The in vitro test results, which are very hard to be compatible with in vivo test results due to the prevention of the interaction with formations such as the extracellular matrix structure, may be controversial.

The main disadvantage of these cell lines is that they do not completely have genotypic and phenotypic features since they are genetically modified. Our present study pioneers as we used human cultures.

Liang et al. synthesized NP cells, collagen fibrillaries, and proteoglycan aggrecans (13). They reported that they are chondrocyte-like cells which resist to over loading, and they play an important role in intervertebral disc. They used stable transfection of recombinant human telomerase reverse transcriptase (hTERT) gene and tested the characteristics and production of NPC lines, which had been immortalized from NPCs. When the first generation was compared with normal NPCs, there was an increase in IGF- 1 and TGF- $\beta$ gene expression in the environment of NPCs transfected by hTERT. In addition, this first generation was faster to proliferate. Surprisingly, Liang et al. emphasized that there was no significant change in COL2A1, proteoglycan, or aggrecan expression (13).

Wang et al. indicated that biological repair of IVD could be used in cell-based treatments (28), yet the response of NPCs to such repair is not known. They used 20 human degenerated $\mathrm{NP}$ lines and emphasized that there was no significant difference in COL2A1 expression given different distribution cell cycles or apoptosis levels.

Hudson and Bonassarindicated that, in cultures of 3D structures in a hypoxic environment, human mesenchymal cell cultures increased their production of extracellular matrix products and maintained chondrogenesis in primary intervertebral disc cells (9). In their study, which they conducted in both hypoxic and normoxic environments, they reported that NP in cultures in a hypoxic environment exhibited increased COL2A1 and glycosaminoglycan expression.

In line with previous studies, the authors of this study observed that HIF-1a gene expression value, which is related to hypoxia, and COL2A1 expression had a negative correlation with cell proliferation time.

Chou et al. discovered that repair or regeneration of human AF tissue plays a key role in restoration and permanency of the functions of NP tissue (3). They evaluated the response of growth factors in different combinations in human AFCs, so 
they prepared monolayer cell cultures by taking degenerated disc tissue samples during intervertebral discectomy. They prepared transforming growth factor beta-1 (TGF- $\beta 1$ ) (Group 2) and fibroblast growth factor-2 (FGF-2) (Group 3) in culture environments and used different protocols for each group for 14 days. In the control group, cell cultures without growth factors were used (Group 1). Group 4 was comprised of an environment containing both TGF and FGF. They evaluated Group 5, whose culture environment contained GFs, for the first 10 days and added a TGF- $\beta 1$ supplement for the following four days (3). They carried out these evaluations by comparing cell proliferations, collagen, and non-collagen extracellular matrix products and gene expressions across the groups. They reported higher levels of cell proliferation in Groups 4 and 5 than in Groups 1, 2, and 3. They concluded that extracellular matrix gene expression was significantly higher in Groups 4 and 5 than in the other groups (3).

In a similar study, Wang et al. used a qRT-PCR methodology (29). They reported that bone morphogenetic factor-7 played an essential role in cell hemostasis and in regulating the anabolism and catabolism of intervertebral discs. They maintained that IVD could be treated by means of combinations of BMP-7 and FoxC2 were used.

Stich et al. indicated that cell-based regenerative approaches could be advised as a primary or adjuvant procedure in order to prevent degeneration in IVD treatment (24). They tested middle- and upper-level degenerated cervical NP cells in terms of cell renewal, proliferation, and differentiation. In addition, they examined cell surface markers in cell cultures. They used NP tissues were obtained from 10 cases with IVD. During culturalization, they created groups with growth factor and non-growth factor. Afterwards, they compared ACAN, COLIA, and COL2A1 expressions, which are NP reagents. They concluded that the presence of a Fas receptor might lead to negative results in potential therapeutic applications after an excessive expression. They emphasized that these kinds of cells could be the target of cytotoxic T-cell activity induced by Fas ligand and activated by apoptosis.

Van den Akker et al. investigated whether clonal cell lines, which represent subpopulations unlike clonal human NP, could produce healthy NP cells from non-degenerated IVD tissue by manipulating apoptosis strategies (27). In their research, they used healthy waste disc materials obtained from patients between 8-15 years of age who had undergone operations. In NP monolayer cell cultures, they used the simian virus 40 large T antigen (SV4OLTag) and the human telomerase reverse transcriptase expression vector during phase passage. Afterwards, they compared COL1A1, COL2A1, and SOX9 expressions in a culture environment. Under traditional differentiation conditions, they characterized two predominant clonal NP subtypes that might stimulate SOX9 and COL2A and had suitable morphologic features. They inferred that cell treatment could be promising in the analysis and treatment of IVD disease.

In a similar study in which primary cells isolated from rat caudal discs were used, physical culture configurations were created, which were comprised of mediums with different levels of oxygen and alpha-MEM, opti-MEM, and DMEM. The behavior of cells was examined in different cultural environments. As a result, high proliferation levels were seen in cultures in which DMEM and Opti-MEM were used. In addition, the gene expression patterns of cells in monolayer cultures with DMEM were compatible with the delayed response caused by dedifferentiation and hypoxia (20).

For this reason, in the present study, we have used DMEM cell culture medium. We have not used any cell culture medium to supplement the human primary cell culture containing growth factor. The researchers did not use any vectorial agent supplements to suppress gene expression during the post transcriptional phrase.

The patients whose degenerated or intact tissues were used were between 26 and 56 years of age. Surgical techniques were used in the preparation of cell cultures from degenerated tissues in patients with disc hernia who had undergone lumbar microdiscectomy.

While preparing cell cultures from intact tissues, the authors of the present study used tissues from patients who had undergone traumatic intervertebral discectomy after spinal trauma and corpectomy together with discectomy.

Gawri et al. attempted to discover which inflammatory receptors and cytokines were upgraded in human intervertebral cells exposed to high mechanical stress (HMS) at a low frequency (6). They used cellular and molecular methodology in their research and prepared isolated human AFC and NPCs. They compared static control cultures, which were exposed to HMS on silicone rubber plates fastened to a mechanic tension device. The researchers then evaluated the gene expression of toll-like receptors (TLRs), neuronal growth factor (NGF), and tumor necrosis factor alpha (TNF-a). They reported that HMS caused upregulation of gene expression of TLR2, TLR4, NGF, and TNFa in IVD cultures. In the medium, which was obtained from HSM cultures, they found that it contained growth-related oncogene; interleukin (IL)-6, IL-8, IL-15; monocyte chemoattractant protein (MCP)-1; MCP3; monokine induced by $\gamma$ interferon; TGF- $\beta 1$; TNF- $\alpha$; and NGF on high levels. They concluded that HMS in in vitro cell cultures stimulated degenerative disc disease, inflammatory responses, and cytokines, all of which are related to lumbar pain.

Chon et al. reported that pathologies could be decelerated, and regeneration of tissues supported thanks to cell cultures in degenerated or herniated intervertebral disc tissues (2). To this end, they used human umbilical cord mesenchymal stromal cells (HUCMSCs) originating from Wharton's jelly cultures. They cultured cells in a hypoxic environment, with differentiation condition. They arranged NPC cell environments in which a commercial gel system without serum, insulin-like growth factor-1, or TGF- $\beta 1$ was used. They reported that in rich lamina environments, HSCMSCs have the potential to differentiate to immature NP cells that share their features. The researchers also concluded that HSCMCSs may be useful in treatment for IVD.

The authors of the present study did not find any relationship between the type of tissue and proliferation ( $r=0.000 ; p=1.000)$. Similarly, there was no relationship identified between the type 
of tissue and HIF-1a gene expression ( $r=0.098 ; p=0.245)$. In all other binary combinations, the researchers found statistically meaningful relationships (Type of tissue-MTT cell proliferation $[r=0.275 ; p=0.001]$; Type of tissue-CHAD [ $r=0.293 ; p=0.000]$; and type of tissue-COL2A1 $(r=0.447 ; p=0.000)]$. In brief, the researchers observed a significant relationship among all variants except for the relationship between proliferation time and tissue type. However, it was reported that the relationship between time and HIF-1a and COL2A1 expression was negative (Time-MTT cell proliferation $[r=0.410 ; p=0.000]$; TimeCHAD [ $r=0.239 ; p=0.004]$; Time- HIF-1a [ $r=-0.837 ; p=0.000]$; Süre-COL2A1 [ $r=-0.548 ; p=0.000)]$. Moreover, the correlation between MTT cell proliferation and HIF-1a, between MTT cell proliferation and COL2A1, CHAD and among HIF-1a, and CHAD and COL2A1 were meaningful, and as respectively follows ; $r=-0.379 ; p=0.000),(r=-0.195 ; p=0.019),((r=0.194$; $p=0.020)$, and $(r=0.796 ; p=0.000)$, respectively. However, it should be kept in mind that the data were obtained from human primary cell cultures set up in an in vitro environment. Furthermore, the limited number of samples and the fact that tissues were taken from the patients of the same race are limitations of this study.

\section{CONCLUSION}

Pharma-molecular and pharma-economic studies have gained momentum recently in line with the increase of the use of array-based systems. Thus, cell-based studies have increased in popularity, although how much of the resulting data is useful in clinical practice is questionable; the efficacy of regenerative treatments is still open to discussion. As a result, canalizing the data obtained from cell-based research into treatments is one of the main difficulties to be overcome.

\section{REFERENCES}

1. Best MJ, Buller LT, Falakassa J, Vecchione D: Risk factors for nonroutine discharge in patients undergoing spinal fusion for intervertebral disc disorders. lowa Orthop J 35: 147-155, 2015

2. Chon BH, Lee EJ, Jing L, Setton LA, Chen J: Human umbilical cord mesenchymal stromal cells exhibit immature nucleus pulposus cell phenotype in a laminin-rich pseudo-threedimensional culture system. Stem Cell Res Ther 4:120, 2013

3. Chou PH, Wang ST, Ma HL, Liu CL, Chang MC, Lee OK: Development of a two-step protocol for culture expansion of human annulus fibrosus cells with TGF- $\beta 1$ and FGF-2. Stem Cell Res Ther 7: 89, 2016

4. Ehlicke F, Freimark D, Heil B, Dorresteijn A, Czermak P: Intervertebral disc regeneration: Influence of growth factors on differentiation of human mesenchymal stem cells (hMSC). Int J Artif Organs 33: 244-252, 2010

5. Feng G, Jin X, Hu J, Ma H, Gupte MJ, Liu H, Ma PX: Effects of hypoxias and scaffold architecture on rabbit mesenchymal stem cell differentiation towards a nucleus pulposus-like phenotype. Biomaterials 32: 8182-8189, 2011

6. Gawri R, Rosenzweig DH, Krock E, Ouellet JA, Stone LS, Quinn TM, Haglund L: High mechanical strain of primary intervertebral disc cells promotes secretion of inflammatory factors associated with disc degeneration and pain. Arthritis Res Ther 16: R21, 2014
7. Gumustas F, Yilmaz I, Sirin DY, Gumustas SA, Batmaz AG, Isyar M, Akkaya S, Mahirogullari M: Chondrocyte proliferation, viability, and differentiation is declined following administration of methylphenidate utilized for the treatment of attention deficit/hyperactivity disorder. Hum Exp Toxicol 36: 981-992, 2017

8. Gumustas SA, Yilmaz I, Isyar M, Sirin DY, Batmaz AG, Ugras AA, Oznam K, Ciftci Z, Mahirogullari M: Assessing the negative impact of phenyl alkanoic acid derivative, a frequently prescribed drug for the suppression of pain and inflammation, on the differentiation and proliferation of chondrocytes. $J$ Orthop Surg Res 11(1): 70, 2016

9. Hudson KD, Bonassar LJ: Hypoxic expansion of human mesenchymal stem cells enhances three-dimensional maturation of tissue-engineered intervertebral discs. Tissue Eng Part A 23: 293-300, 2017

10. Hunter W: On the structure and diseases of articulating cartilage. Philos Trans R Soc Lond 42: 514-521, 1743

11. Isyar M, Yilmaz I, Yasar Sirin D, Yalcin S, Guler O, Mahirogullari M: A practical way to prepare primer human chondrocyte culture. J Orthop 13: 162-167, 2016

12. Komur B, Akyuva Y, Karaslan N, Isyar M, Gumustas SA, Yilmaz I, Akkaya S, Sirin DY, Mutlu CA, Batmaz AG, Guler O, Mahirogullari M: Can a biodegradable implanted bilayered drug delivery system loaded with BMP-2/BMP-12 take an effective role in the biological repair process of bone-tendon injuries? A preliminary report. J Pharm (Cairo) 2017:7457865, 2017

13. Liang W, Ye D, Dai L, Shen Y, Xu J: Overexpression of hTERT extends replicative capacity of human nucleus pulposus cells, and protects against serum starvation-induced apoptosis and cell cycle arrest. J Cell Biochem 113: 2112-2121, 2012

14. Liu H, Huang X, Liu X, Xiao S, Zhang Y, Xiang T, Shen X, Wang $G$, Sheng B: miR-21 promotes human nucleus pulposus cell proliferation through PTEN/AKT signaling. Int J Mol Sci 15: 4007-4018, 2014

15. Liu Q, Dinu I, Adewale AJ, Potter JD, Yasui Y: Comparative evaluation of gene-set analysis methods. BMC Bioinformatics 8: 431,2007

16. May RD, Tekari A, Frauchiger DA, Krismer A, Benneker LM, Gantenbein B: Efficient nonviral transfection of primary intervertebral disc cells by electroporation for tissue engineering application. Tissue Eng Part C Methods 23: 3037,2017

17. Mern DS, Thomé C: Identification and characterization of human nucleus pulposus cell specific serotypes of adenoassociated virus for gene therapeutic approaches of intervertebral disc disorders. BMC Musculoskelet Disord 16: 341,2015

18. Overley SC, McAnany SJ, Brochin RL, Kim JS, Merrill RK, Qureshi SA: The 5-year cost-effectiveness of two-level anterior cervical discectomy and fusion or cervical disc replacement: A Markov analysis. Spine J 18(1): 63-71, 2018

19. Oznam K, Sirin DY, Yilmaz I, Kaya YE, Isyar M, Gumustas SA, Ozbek H, Akkaya S, Kayhan A, Mahirogullari M: lopromideand gadopentetic acid-derived preparates used in MR arthrography may be harmful to chondrocytes. J Orthop Surg Res 12: 98, 2017 
20. Rastogi A, Thakore P, Leung A, Benavides M, Machado M, Morschauser MA, Hsieh $\mathrm{AH}$ : Environmental regulation of notochordal gene expression in nucleus pulposus cells. J Cell Physiol 220: 698-705, 2009

21. Rosai J: Rosai and Ackerman's Surgical Pathology. 9th ed. Vol: 2, Mosby, 2004:2204

22. Rosenzweig DH, Carelli E, Steffen T, Jarzem P, Haglunf L: 3D-printed ABS and PLA scaffolds for cartilage and nucleus pulposus tissue regeneration. Int J Mol Sci 16: 15118-15135, 2015

23. Rosenzweig DH, Tremblay Gravel J, Bisson D, Ouellet JA, Weber $\mathrm{MH}$, Haglund L: Comparative analysis in continuous expansion of bovine and human primary nucleus pulposus cells for tissue repair applications. Eur Cell Mater 33: 240-251, 2017

24. Stich S, Stolk M, Girod PP, Thomé C, Sittinger M, Ringe J, Seifert M, Hegewald AA: Regenerative and immunogenic characteristics of cultured nucleus pulposus cells from human cervical intervertebral discs. Plos One 10: e0126954, 2015

25. Topuk S, Akyuva Y, Karaaslan N, Mutlu CA, Yilmaz I, Isyar M, Sirin DY, Akkaya S, Özbek H, Mahirogullari M: Is it possible to treat osteosarcoma using oligonucleotides confined into controlled release drug delivery systems? Curr Pharm Biotechnol 18: 516-522, 2017

26. Vadalà G, Russo F, Ambrosio L, Loppini M, Denaro V: Stem cells sources for intervertebral disc regeneration. World $\mathrm{J}$ Stem Cells 8: 185-201, 2016

27. van den Akker GG, Surtel DA, Cremers A, Rodrigues-Pinto $\mathrm{R}$, Richardson SM, Hoyland JA, van Rhijn LW, Welting TJ, Voncken JW: Novel immortal human cell lines reveal subpopulations in the nucleus pulposus. Arthritis Res Ther 16: R135, 2014
28. Wang F, Wu XT, Zhuang SY, Wang YT, Hong X, Zhu L, Bao JP: Ex vivo observation of human nucleus pulposus chondrocytes isolated from degenerated intervertebral discs. Asian Spine J 5: 73-81, 2011

29. Wang Z, Fu C, Chen Y, Xu F, Wang Z, Qu Z, Liu Y, Fox C: Enhances BMP7-mediated anabolism in nucleus pulposus cells of the intervertebral disc. Plos One 11: e0147764, 2016

30. Watanabe M, Sakai D, Yamamoto Y, Sato M, Mochida J: Upper cervical spine injuries: Age-specific clinical features. J Orthop Sci 15: 485-492, 2010

31. Weiler C, Lopez-Ramos M, Mayer HM, Korge A, Siepe CJ, Wuertz K, Weiler V, Boos N, Nerlich AG: Histological analysis of surgical lumbar intervertebral disc tissue provides evidence for an association between disc degeneration and increased body mass index. BMC Res Notes 4: 497, 2011

32. Xiong X, Dai L, Liang W, Zhang J, Qin S, Cao W, Ye D, Liang P, Liu Z: Protective effect of p53 on the viability of intervertebral disc nucleus pulposus cells under low glucose condition. Biochem Biophys Res Commun 490: 1414-1419, 2017

33. Zhou X, Tao Y, Liang C, Zhang Y, Li H, Chen Q: BMP3 alone and together with TGF- $\beta$ promote the differentiation of human mesenchymal stem cells into a nucleus pulposus-like phenotype. Int J Mol Sci 16: 20344-20359, 2015

34. Zhu Y, Liang Y, Zhu H, Lian C, Wang L, Wang Y, Gu H, Zhou $G$, Yu X: The generation and functional characterization of induced pluripotent stem cells from human intervertebral disc nucleus pulposus cells. Oncotarget 8: 42700-42711, 2017 